\title{
Doxorubicin sensitizes breast cancer cells to natural killer cells in connection with increased Fas receptors
}

\author{
NUNGHATHAI SAWASDEE ${ }^{1,2}$, METHICHIT WATTANAPANITCH ${ }^{3}$, NONTAPHAT THONGSIN $^{3,4}$, \\ NATTAPORN PHANTHAPHOL ${ }^{1,2,4}$, CHUTIPA CHIAWPANIT ${ }^{5}$, CHANITRA THUWAJIT $^{4}$, \\ PA-THAI YENCHITSOMANUS ${ }^{1,2}$ and AUSSARA PANYA ${ }^{5,6}$
}

\begin{abstract}
${ }^{1}$ Siriraj Center of Research Excellence for Cancer Immunotherapy, Faculty of Medicine Siriraj Hospital, Mahidol University;
${ }^{2}$ Division of Molecular Medicine, Research Department, Faculty of Medicine Siriraj Hospital, Mahidol University;

${ }^{3}$ Siriraj Center for Regenerative Medicine, Research Department, Faculty of Medicine Siriraj Hospital, Mahidol University;

${ }^{4}$ Department of Immunology, Faculty of Medicine Siriraj Hospital, Mahidol University, Bangkok 10700;

${ }^{5}$ Department of Biology and ${ }^{6}$ Research Center in Bioresources for Agriculture, Industry and Medicine,

Faculty of Science, Chiang Mai University, Chiang Mai 50200, Thailand
\end{abstract}

Received November 1, 2021; Accepted January 12, 2022

DOI: $10.3892 / \mathrm{ijmm} .2022 .5095$

\begin{abstract}
Breast cancer (BC) is the most common cancer in women. Although standard treatments are successful in patients with $\mathrm{BC}$ diagnosed at an early stage, an alternative treatment is required for patients with advanced-stage disease who do not respond to these treatments. The concept of using chemotherapy to sensitize cancer cells to become susceptible to immunotherapy was recently introduced and may be used as an alternative treatment for BC. The chemotherapeutic drug doxorubicin has been reported to sensitize cancer cells; however, the efficacy to sensitize the solid spheroids, in addition to its underlying mechanism regarding how doxorubicin sensitizes BC, has not previously been explored. In the present study, the effectiveness of a combined treatment of doxorubicin and natural killer-92 (NK-92) cells against BC in either 2D or 3D spheroid models, and its association with Fas receptor (FasR) expression, was demonstrated. The BC (MCF7) cell line expressing a higher level of FasR was more sensitive to NK-92 cell killing than the MDA-MB-231 cell line, which expressed a lower level of FasR. A sublethal dose of doxorubicin caused a significant improvement in NK cytotoxicity. Concordantly, a significant reduction in cell viability was observed in the doxorubicin-treated MCF7 spheroids. Notably, flow cytometric analysis revealed significantly increased FasR expression in the MCF7 cells, suggesting the underlying
\end{abstract}

Correspondence to: Dr Aussara Panya, Department of Biology, Faculty of Science, Chiang Mai University, 293 Hauy Kaew Road, Muang, Chiang Mai 50200, Thailand

E-mail: aussara.pan@cmu.ac.th; sapaya116@gmail.com

Key words: natural killer cells, doxorubicin, immunotherapy, combined chemotherapy-immunotherapy, breast cancer, immunomodulation activity sensitization mechanism of doxorubicin in $\mathrm{BC}$ was related to the FasR upregulation. The present findings supported the use of combined doxorubicin and NK immunotherapy in $\mathrm{BC}$ treatment.

\section{Introduction}

Breast cancer (BC) is the most common cancer diagnosed in women worldwide (1), and it is the most commonly diagnosed cancer among women in Thailand (2). The standard treatments for BC include local treatment (resection and radiotherapy) and systemic therapy (chemotherapy, endocrine therapy and targeted drug therapy) (3). The clinical outcome is associated with the stage of disease and the molecular characteristics of the cancer diagnosed $(4,5)$. These standard treatments in the early stage of the disease can improve survival-free progression and lower the risk of cancer recurrence and mortality. Patients diagnosed with stage I BC have prolonged survival (5- to 30-year follow-up) compared with those diagnosed with stage II BC (6). However, an alternative therapeutic option is urgently required for those with advanced stages, and for those who do not respond to the traditional standard treatments.

Immunotherapy functions by prompting the immune system to fight against cancer, since host immunity is the key element for controlling carcinogenesis, progression and metastasis (7). Components of the immune system, such as antibodies and immune cells, are used as biological therapeutics to eliminate and control cancer cells. The success of immunotherapy in several cancer types greatly expands its therapeutic utility in modern cancer therapy $(7,8)$. Several immunotherapy drugs have been approved by the U.S. Food and Drug Administration (9,10), and a large number of clinical trials are ongoing (11-13). Natural killer (NK) cells belonging to the innate immune system are an attractive choice for adoptive immunotherapy. NK cells directly attack cancer cells without prior sensitization (12) in a non-major histocompatibility complex (MHC)-restricted manner. NK cells can lyse cancer 
cells via various mechanisms, including antibody-dependent cellular cytotoxicity, the release of cytolytic granules (perforin and granzyme) and expression of death receptor-mediated apoptosis [TNF-related apoptosis-inducing ligand (TRAIL) and Fas signaling pathway] (14). Adoptive NK cell immunotherapy is an attractive approach that has been tested in patients with lung cancer, lymphoma, ovarian cancer and BC (12,15-18). A previous study using autologous NK-cell adoptive transfer in patients with metastatic melanoma or renal cell carcinoma revealed the persistence of adoptive NK cells in the peripheral circulation for weeks to months after treatment; however, the adoptive NK cells had low cytotoxic activity and failed to mediate tumor regression (18). This was due to the inhibitory signal from self MHC I-expressing tumor cells that prevented the autologous NK cells from attacking cancer cells. Accordingly, allogeneic NK cell therapy has gained significant attention. Taking advantage of the inhibitory ligand mismatch, allogeneic NK cells demonstrated a markedly improved outcome in myeloid leukemia after haploidentical hematopoietic cell transplantation (19). However, the therapeutic potential of adoptive NK cell transfer remains limited by several factors, one of which is the failure of NK expansion in vivo (20). Therefore, the in vivo persistence of $\mathrm{NK}$ cells and their rapid actions are likely the critical factors that influence their antitumor activity. One strategy to augment the NK killing function is to render tumor cells more susceptible to NK cytotoxicity, which causes the rapid killing of tumors in a shorter period.

Previously, the combined effects of chemotherapeutic drugs and immunotherapy have been reported to enhance the cytotoxic activity of immunotherapy against cancer cells and promote the therapeutic effect (21). Sensitization of cancer cells involves the upregulation of activating ligand expression, which causes the cancer cells to be more susceptible to killing by immune cells. Previously, the treatment with a sublethal dose of doxorubicin was shown to promote tumor cell susceptibility to NK and T lymphocytes (22). Doxorubicin, which is an anthracycline antibiotic drug, is the first-line therapy for the treatment of different cancer types, including leukemia, Hodgkin's lymphoma, lung cancer, BC and others (23). In $\mathrm{BC}$, doxorubicin treatment yielded improved progression-free survival and median survival duration in patients with metastasis compared with paclitaxel treatment (24); however, the underlying mechanism of doxorubicin on the sensitization of $\mathrm{BC}$ has not yet been elucidated.

To investigate the sensitization mechanism of doxorubicin in $\mathrm{BC}$, the killing activity of $\mathrm{NK}$ cells in two different $\mathrm{BC}$ cell lines, including MCF7 (ER $\left.{ }^{+} / \mathrm{PR}^{+} / \mathrm{HER}^{-}\right)$and MDA-MB-231 (ER $/ \mathrm{PR}^{-} / \mathrm{HER}^{-}{ }^{-}$, with and without doxorubicin treatment, was compared in the present study. The cytotoxicity of doxorubicin and its ability to sensitize MCF7 and MDA-MB-231 cells to NK-92 cell killing was investigated. It was demonstrated that the treatment with a sublethal dose of doxorubicin caused MCF7, but not MDA-MB-231 cells, to become more sensitive to NK-92 cells and primary NK cells isolated from healthy donors via upregulation of Fas-receptor (FasR) expression. The knowledge obtained from the present study supports the use of a combined chemotherapy-immunotherapy regimen for the treatment of $\mathrm{BC}$, and suggests that FasR could be used as a marker for predicting the response to combined doxorubicin-NK cell therapy.

\section{Materials and methods}

Cell culture. BC cell lines, MCF7 ( $\left.\mathrm{ER}^{+} / \mathrm{PR}^{+} / \mathrm{HER} 2^{-}\right)$, T47D $\left(\mathrm{ER}^{+} / \mathrm{PR}^{+} / \mathrm{HER}^{-}\right)$and $\mathrm{MDA}-\mathrm{MB}-231$ (ER $\left./ \mathrm{PR}^{-} / \mathrm{HER} 2^{-}\right)$were obtained from the American Type Culture Collection (ATCC) and maintained in Dulbecco's modified Eagle's medium (DMEM; Gibco; Thermo Fisher Scientific, Inc.) supplemented with $10 \%$ fetal bovine serum (FBS; Gibco; Thermo Fisher Scientific, Inc.), and $100 \mathrm{mg} / \mathrm{ml}$ of penicillin/streptomycin (MilliporeSigma). The lymphoblast cell line K562 was obtained from the ATCC and maintained in Roswell Park Memorial Institute-1640 (RPMI-1640; Gibco; Thermo Fisher Scientific, Inc.) supplemented with $10 \%$ FBS and $100 \mathrm{mg} / \mathrm{ml}$ penicillin/streptomycin. An NK cell line, namely NK-92, was purchased from the ATCC and maintained in Minimum Essential Medium Eagle- $\alpha$ Modification supplemented with $12.5 \%$ horse serum (Gibco; Thermo Fisher Scientific, Inc.) and $12.5 \%$ FBS, $0.2 \mathrm{mM}$ inositol, $0.1 \mathrm{mM}$ 2-mercaptoethanol, $0.02 \mathrm{mM}$ folic acid and 100-200 U/ml recombinant IL-2 (R\&D Systems, Inc.). Mycoplasma testing was performed for the cell lines used. The cells were cultured at $37^{\circ} \mathrm{C}$ in a $5 \% \mathrm{CO}_{2}$ humidified incubator.

Construction and generation of red-fluorescence protein (RFP)-expressing MCF7 and MDA-MB-231 cells. The lentivirus transfer plasmid (pCDH vector) was a kind gift from Associate Professor Naravat Poungvarin (Faculty of Medicine Siriraj Hospital, Mahidol University, Thailand). The RFP-encoding lentivirus, namely pCDH-RFP, was constructed by cloning the RFP coding sequences to the vector backbone. Using the 2nd generation lentivirus packing system, the construct (500 ng) was used to transfect into the 293T cells (ATCC; $5 \times 10^{5}$ cells in a $35-\mathrm{mm}$ dish; maintained in DMEM supplemented with $10 \% \mathrm{FBS}$ and $100 \mathrm{mg} / \mathrm{ml}$ penicillin/streptomycin), together with $50 \mathrm{ng}$ of envelope (pMD2.G) and $500 \mathrm{ng}$ of packaging plasmids (psPAX2) to produce the lentivirus using the Lipofectamine ${ }^{\circledR} 2000$ (Thermo Fisher Scientific, Inc.) according to the manufacturer's protocol. The cells were incubated for $6 \mathrm{~h}$ at $37^{\circ} \mathrm{C}$, and the $2 \mathrm{ml}$ of fresh media was replaced. The lentivirus was harvested at $48 \mathrm{~h}$ after transfection and titrated using qPCR Lentivirus Titer kit (cat. no. LV900; Applied Biological Materials). The virus was used to transduce the MCF7 and MDA-MB-231 cells at a multiplicity of infection of 100 for $24 \mathrm{~h}$. Subsequently, puromycin (Thermo Fisher Scientific, Inc.) was added at the concentration of $2 \mu \mathrm{g} / \mathrm{ml}$ for 3 weeks (replacing the fresh media containing puromycin every 3 days thereafter) to select the stable RFP-expressing cells used in the killing assay.

Isolation and culture of primary NK cells. Peripheral blood mononuclear cells (PBMCs) were isolated from two healthy donors using Lymphocyte Separation Medium (Corning, Inc.) according to the manufacturer's protocol. The present study was conducted according to the guidelines of the Declaration of Helsinki and was approved (approval no. COA 286/2021) by the Siriraj Institutional Review Board of the Faculty of Medicine Siriraj Hospital (Bangkok, Thailand). Written consent was obtained during April-June 2021 and followed the approved protocol by which all donors agreed to the use of their samples in scientific research. The primary NK cells 
were sorted using CD56 MicroBeads (Miltenyi Biotec GmbH) according to the manufacturer's protocol. The primary NK cells were maintained in RPMI-1640 medium, 10\% FBS, 2 mM GlutaMAX ${ }^{\mathrm{TM}}$ (Gibco; Thermo Fisher Scientific, Inc.), $1 \%$ non-essential amino acid and $1 \%$ penicillin/streptomycin, supplemented with $100 \mathrm{U} / \mathrm{ml}$ recombinant IL-2. The $\mathrm{CD}^{2} 6^{+}$cells were expanded by co-culturing with irradiated membrane-bound IL-21 expressing K562 cells (artificial antigen-presenting cells) at a 1:1 ratio in the culture medium supplemented with $100 \mathrm{U} / \mathrm{ml}$ recombinant IL-2. The NK cells were expanded for 6 days, with the medium being changed on day 3 of co-culture.

Cell viability assay. The cytotoxicity of doxorubicin (MilliporeSigma) was evaluated in the MCF7 and MDA-MB-231 cells using a cell viability assay. The cells were plated in a 96-well plate at a density of 7,000 cells/well 1 day before the experiment. Various concentrations of doxorubicin $(0,0.0064,0.032,0.16,0.8,4,20$ and $100 \mu \mathrm{M})$ were prepared in complete media (10\% FBS DMEM) and added to the cells. Cell viability was determined after $24 \mathrm{~h}$ of incubation at $37^{\circ} \mathrm{C}$ in a $5 \% \mathrm{CO}_{2}$ humidified incubator using PrestoBLUE ${ }^{\mathrm{TM}}$ cell viability reagent $(10 \mu 1$ per well; Invitrogen; Thermo Fisher Scientific, Inc.) to measure the number of living cells. The reducing viability of the treated cells reflected by the color changes of reagent were measured by monitoring the absorbance at $570 \mathrm{~nm}$ and the absorbance at $600 \mathrm{~nm}$ (a reference wavelength) using a Synergy Mx Microplate reader (BioTek Instruments Inc.). The results are presented as the percentage of cell viability relative to that of the non-treated cells, which was set as $100 \%$ using the following equation: \% cell viability $=\left[(\mathrm{OD} 570-\mathrm{OD} 595)_{\text {treated cells }} /\right.$ (OD570-OD595) non-treated cells x100. The data were used to calculate the half-maximal cytotoxic concentration $\left(\mathrm{CC}_{50}\right)$ using non-linear regression and GraphPad Prism software version 8 (GraphPad Software, Inc.).

Flow cytometric analysis. Primary NK cells were propagated in vitro and characterized by flow cytometry. Expanded CD $56^{+}$ NK cells were harvested via centrifugation $\left(800 \mathrm{xg}\right.$ ) at $4^{\circ} \mathrm{C}$ for 5 min and stained with monoclonal antibodies (at 1:50 dilution), including anti-human CD45-PerCP (cat. no. 368506), anti-human CD56-PE/Cy7 (cat. no. 362510), anti-human CD3-FITC (cat. no. 300406) and anti-human CD16-BV650 (cat. no. 302041) (all from BioLegend, Inc.), for $15 \mathrm{~min}$ at room temperature. A Zombie Violet ${ }^{\mathrm{TM}}$ Fixable Viability kit (BioLegend, Inc.) was used to exclude dead cells according to the manufacturer's protocol. Non-specific background signal was determined using isotype-control antibodies (at 1:50 dilution), including PerCP mouse IgG1 (cat. no. 400148), $\mathrm{PE} / \mathrm{Cy} 7$ mouse IgG1 (cat. no. 400125), FITC mouse IgG1 (cat. no. 400108) and BV650 mouse IgG1 (cat. no. 400163) (all from BioLegend, Inc.), for $15 \mathrm{~min}$ at room temperature. The stained cells were analyzed using BD LSRFortessa ${ }^{\mathrm{TM}}$ flow cytometer (BD Biosciences) and FlowJo software version 10 (BD Biosciences).

The effect of doxorubicin on surface protein expression was investigated. MCF7 and MDA-MB-231 cells were plated onto a 24-well plate at a density of 30,000 cells/well 1 day before the experiment. Doxorubicin was added to the cells at various concentrations $(0,40,80$ and $160 \mathrm{nM})$. The cells were cultured for $24 \mathrm{~h}$ at $37^{\circ} \mathrm{C}$, in a $5 \% \mathrm{CO}_{2}$ cell culture incubator, and harvested for flow cytometric analysis. Briefly, MCF7 and MDA-MB-231 cells were harvested via centrifugation $(800 \mathrm{x} \mathrm{g})$ at $4^{\circ} \mathrm{C}$ for 5 min and incubated with monoclonal antibodies (at 1:50 dilution), including anti-TRAIL1-PE (cat. no. 12-6644-42), anti-TRAIL2-PE (cat. no. 12-9908-42), anti-CD95-APC (cat. no. 17-0959-42), anti-MHC class I polypeptide-related sequence (MIC)-A/B-FITC (cat. no. 53-5788-42), anti-human leukocyte antigen (HLA)-ABC-FITC (cat. no. 11-9983-42) (all Thermo Fisher Scientific, Inc.) and anti-programmed death-ligand 1 (PD-L1)-FITC (cat. no. 393606; BioLegend, Inc.), for $15 \mathrm{~min}$ at room temperature. The respective isotype controls were also obtained from eBioscience; Thermo Fisher Scientific, Inc. The stained cells were analyzed using a BD Accuri ${ }^{\mathrm{TM}}$ C6 Plus flow cytometer (BD Biosciences) using FlowJo software version 10.

Reverse transcription-quantitative polymerase chain reaction $(R T-q P C R)$. The BC cell lines, MCF7 and MDA-MB-231, treated with various concentrations of doxorubicin, were collected for total RNA extraction using TRIzol ${ }^{\circledR}$ reagent (Thermo Fisher Scientific, Inc.). RNA was converted into cDNA using a SensiFAST cDNA Synthesis kit (Bioline; Meridian Bioscience) according to the manufacturer's protocol. The $\mathrm{qPCR}$ analysis was performed using a iCycler $\mathrm{iQ}^{\mathrm{TM}}$ real-time PCR detection system (Bio-Rad Laboratories, Inc.) using the $2 \mathrm{X}$ SensiFast ${ }^{\mathrm{TM}} \mathrm{SYBR}^{\circledast}$ kit (Meridian Bioscience) and the following primers: FasR forward, 5'-ATGCTGGGC ATCTGGACCCT-3' and reverse, 5'-CAACATCAGATAAAT TTATTGCCA-3'; and GAPDH forward, 5'-CGACCACTT TGTCAAGCTCA-3' and reverse, 5'-AGGGGTCTACATGGC AACTG-3'. The PCR conditions were as follows: An initial denaturation step at $95^{\circ} \mathrm{C}$ for $3 \mathrm{~min}$, followed by 40 cycles of denaturation at $95^{\circ} \mathrm{C}$ for $30 \mathrm{sec}$, annealing at $59^{\circ} \mathrm{C}$ for $30 \mathrm{sec}$ and extension at $72^{\circ} \mathrm{C}$ for $45 \mathrm{sec}$. The final extension was performed at $72^{\circ} \mathrm{C}$ for $5 \mathrm{~min}$. The housekeeping gene GAPDH was used to normalize the expression level of each gene. The gene expression fold-change was calculated using the $2^{-\Delta \Delta C q}$ formula (25).

Killing assay. A killing assay was conducted to determine the NK-92 killing activity against BC cells. The MCF7 and MDA-MB-231 cells were genetically engineered to express RFP. The RFP-expressing MCF7 and MDA-MB-231 cells were used to examine the killing efficiency of NK-92 cells. The cells were plated in a 96-well plate at a density of 7,000 cells/well 1 day before the experiment. Co-culture of the effector NK-92 cells (E) and the RFP-expressing MCF7 or MDA-MB-231 target cells $(\mathrm{T})$ was performed using different E:T ratios, including $1: 1,2.5: 1$ and 5:1. At $24 \mathrm{~h}$ after co-culture at $37^{\circ} \mathrm{C}$ in a $5 \% \mathrm{CO}_{2}$ humidified incubator, the NK-92 cells and the dead cells were removed by pipetting and $100 \mu$ PBS was added to the plate. The living cells (attached cells) were visualized under a fluorescent microscope. The proportion of living cells was measured by crystal violet staining at room temperature for $30 \mathrm{~min}$. The stained cells were solubilized in 50\% ethanol and the absorbance was measured at OD590 using the NS-100 Nano Scan microplate reader (Hercuvan Lab Systems). The absorbance values of treated cells were used to calculate the 
A

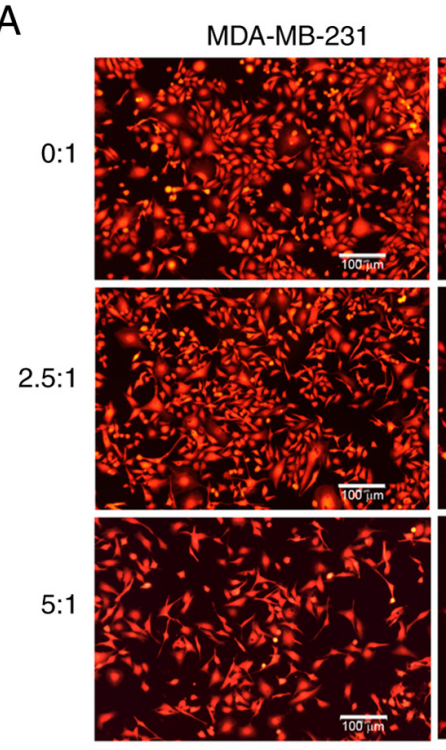

$0: 1$
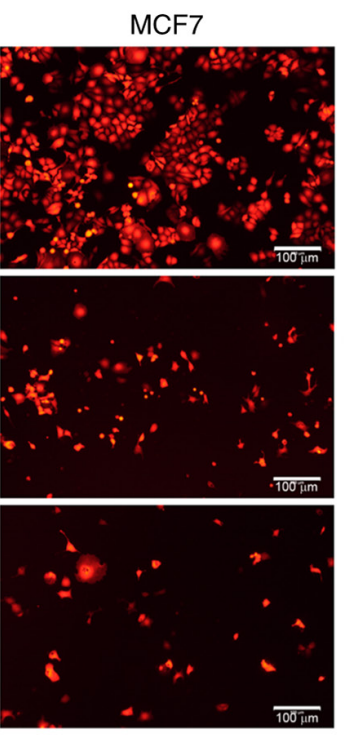

B

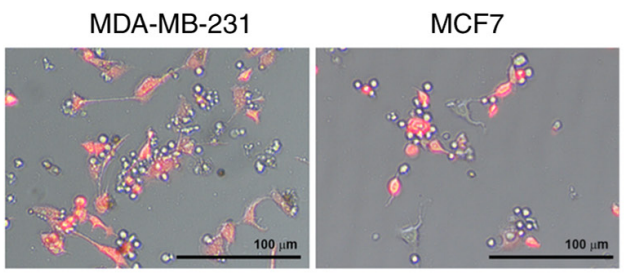

C

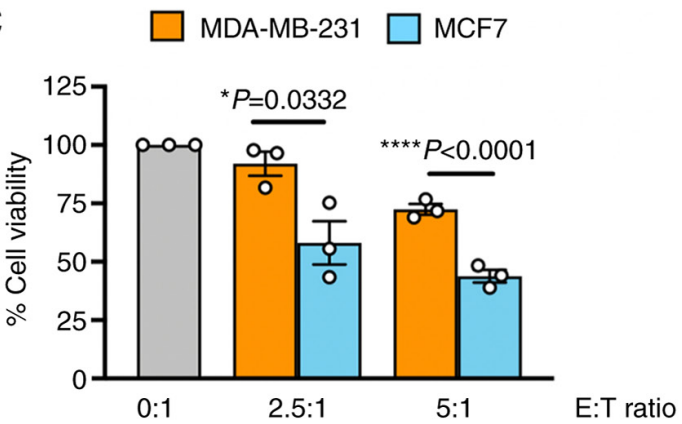

Figure 1. Sensitivity of breast cancer cells to NK cytotoxicity. (A) The cytotoxic ability of the NK-92 cells for killing red fluorescence protein-expressing MDA-MB-231 and MCF7 cells was measured under a fluorescence microscope at different E:T ratios. (B) Representative merged images of the NK-92 cells (no color) and the target cells (red). (C) The viability of the target cells after co-culturing with the NK92 cells. Data were obtained from three independent experiments. Data are presented as the mean \pm SEM. Scale bar, $100 \mu \mathrm{m}$. NK, natural killer; E, effector NK-92 cells; T, MCF7 or MDA-MB-231 target cells.

percentage of living cells relative to the non-treated control (set as $100 \%$ ). Data were analyzed from at least three independent experiments. In a combined treatment of doxorubicin and NK cells, the cancer cells were plated in the presence of $160 \mathrm{nM}$ of doxorubicin for $24 \mathrm{~h}$ before co-culturing with $\mathrm{NK}$ cells at the E:T ratios of 1:1, 2.5:1, and 5:1. The death of the cancer cells was calculated as aforementioned. The killing ability of primary NK cells was also determined. The primary NK cells isolated from two healthy donors were expanded and used for the killing assay, as aforementioned.

Spheroid formation and killing assay of spheroids. In addition, the killing assay was conducted using a 3D spheroid model. Briefly, the MCF7 cells $\left(2 \times 10^{3}\right.$ cells) were labelled with CellTracker ${ }^{\mathrm{TM}}$ Green 5-chloromethylfluorescein diacetate dye (Thermo Fisher Scientific, Inc.) at $37^{\circ} \mathrm{C}$ for $10 \mathrm{~min}$ before seeding onto an ultra-low attachment 96-well round-bottomed plate containing 2.5\% Corning Matrigel matrix (both from Corning, Inc.). The plate was then centrifuged at $1,000 \mathrm{x} \mathrm{g}$ at $4^{\circ} \mathrm{C}$ for $10 \mathrm{~min}$ to allow spheroid formation for $24 \mathrm{~h}$ at $37^{\circ} \mathrm{C}$, in a $5 \% \mathrm{CO}_{2}$ cell culture incubator. Doxorubicin $(320 \mathrm{nM})$ was added to the spheroids for $24 \mathrm{~h}$ before introducing the NK cells in the culture medium at an E:T ratio of 5:1. The remaining living cells were analyzed by confocal microscopy (Nikon Corporation). Images were acquired by Nikon Eclipse Ti confocal microscope and analyzed using the NIS-Element software, version 4.2. Cell viability was calculated using the following formula: (mean fluorescence intensity (MFI) of spheroid with treatment condition/MFI of spheroid alone) x100.

Statistical analysis. All experiments were conducted in triplicate. $\mathrm{P}<0.05$ was used to indicate a statistically significant difference. Data were analyzed using the unpaired Student's t-test for two groups, in addition to a one-way
ANOVA with Tukey's post hoc test for multiple comparisons, using GraphPad Prism software version 8 (GraphPad Software, Inc.).

\section{Results}

MCF7 is more sensitive to NK cytotoxicity than MDA-MB-231. The ability of NK cells to eliminate BC cells was examined in MCF7 cells and the triple-negative BC MDA-MB-231 cells. The viability of cancer cells after $24 \mathrm{~h}$ of co-culturing with NK-92 cells was determined at E:T ratios of 0:1, 2.5:1 and 5:1. The NK-92 cells demonstrated their killing ability in a dose-dependent manner (Fig. 1A). These results merged with cell morphology images revealed that the NK-92 cells promptly attacked the cancer cells, as observed by the NK-92 cells surrounding the $\mathrm{RFP}^{+}$cancer cells after co-culturing (Fig. 1B). The efficiency of NK-92 cells in killing MCF7 was greater than that in the MDA-MB-231 cells at all tested E:T ratios (Fig. 1C). At the highest tested ratio (E:T, 5:1), NK-92 cells caused $56.19 \pm 4.72 \%$ of MCF7 cell death (the cell viability decreased to $43.80 \pm 4.72 \%$ ) whereas it was less efficient in MDA-MB-231 cells by causing $27.55 \pm 3.91 \%$ of death cell (the cell viability decreased to $72.44 \pm 3.91 \%$ ).

Protein expression profiles of TRAIL receptors, FasR, $M I C-A / B$, HLA class $I$ and PD-LI, on MCF7 and MDA$M B-231$ cells. To explain the distinct sensitivity of MCF7 and MDA-MB-231 cells to NK-92 cytotoxicity, the expression levels of TRAIL receptors, FasR, MIC-A/B, HLA class I and PD-L1, were investigated (Fig. 2). Death receptors, including TRAIL receptors and FasR, are involved in NK killing activity, whereas MIC-A/B is the ligand for NK cell activating receptor NKG2D (26). HLA class I is well established as an inhibitory ligand for killer-cell immunoglobulin-like receptors (KIRs) (27). PD-L1 plays a critical role in suppressing NK cell 
A
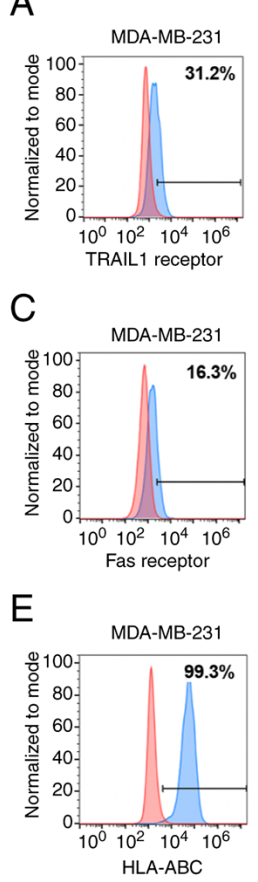
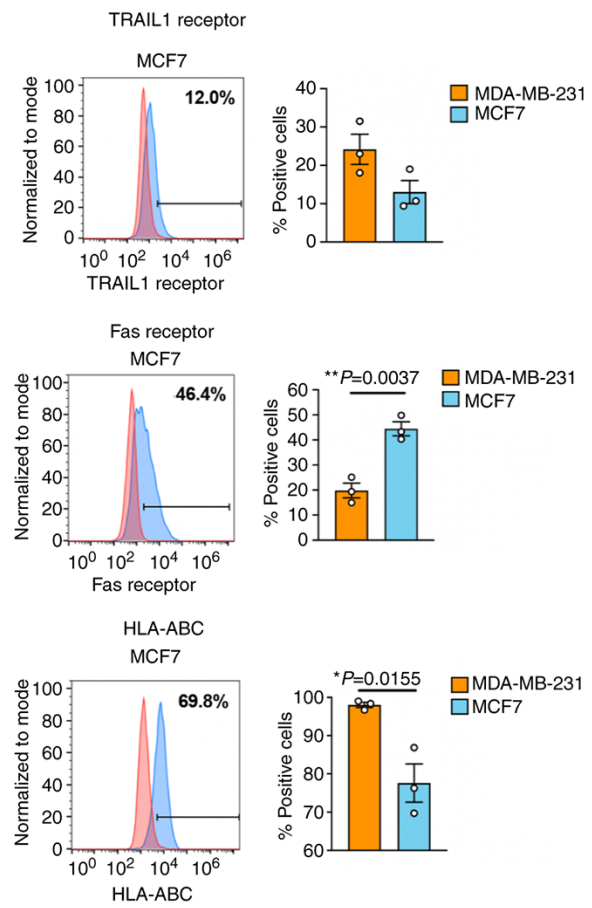

B

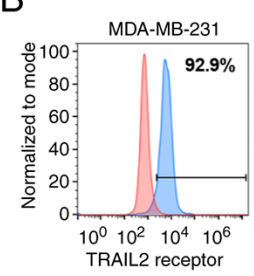

D

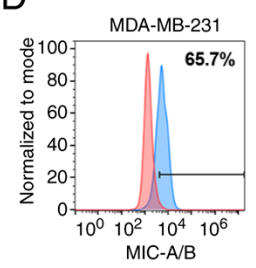

$\mathrm{F}$

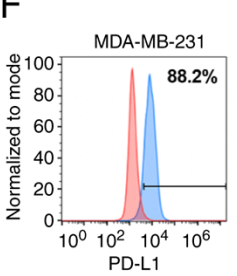

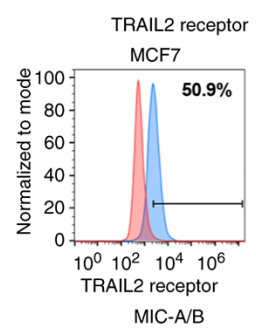
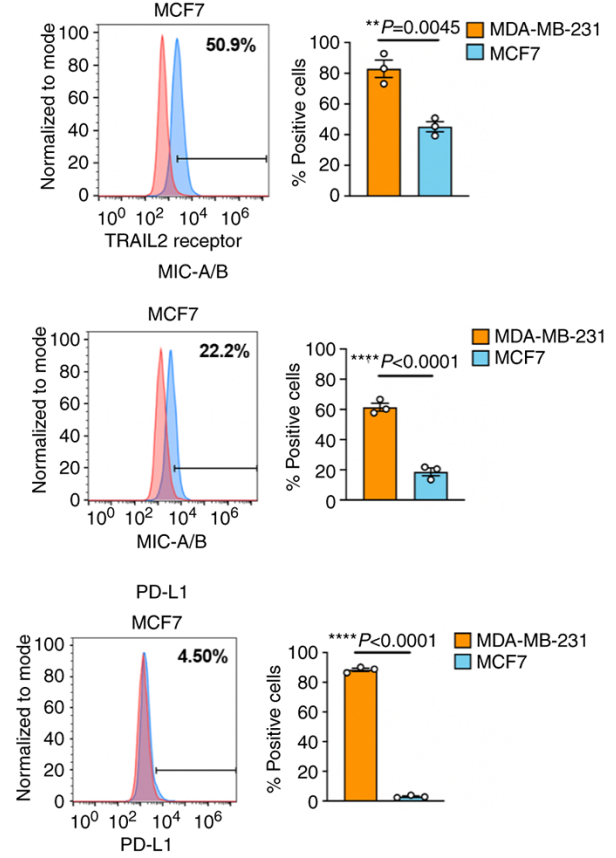

Figure 2. Protein expression profiles of TRAIL receptors, FasR, MIC-A/B, HLA class I and PD-L1 in BC cell lines. The expression profiles of (A) TRAIL1 receptor (A and B) TRAIL2 receptor, (C) FasR, (D) MIC-A/B, (E) HLA class I (ABC) and (F) PD-L1 were compared between two different BC cell lines, MDA-MB-231 (orange bar) and MCF7 (cyan bar), using flow cytometric analysis. Data**) were obtained from three independent experiments. Data are presented as the mean \pm SEM. TRAIL, TNF-related apoptosis-inducing ligand; FasR, Fas receptor; HLA, human leukocyte antigen; PD-L1, programmed death-ligand 1; BC, breast cancer.

function via binding to the PD1 receptor on NK cells (28). Flow cytometric data revealed significant differences in expression between cell lines among these proteins, except for that in the TRAIL1 receptor.

Notably, the death receptors, including TRAIL receptors and FasR, were expressed in both cancer cell lines, but in the opposite manner. The MDA-MB-231 cells expressed higher levels of TRAIL1 and TRAIL2 receptors than those of the MCF7 cells. In more detail, the mean TRAIL1 receptor expression was $24.18 \%$ in the MDA-MB-231 cells compared with $13.04 \%$ in the MCF7 cells and the mean TRAIL2 receptor expression was $82.98 \%$ in the MDA-MB-231 cells compared with $45.17 \%$ in the MCF7 cells. By contrast, the MCF7 cells expressed significantly higher levels of FasR than that of the MDA-MB-231 cells (44.47 vs. 19.81\%) (Fig. 2A-C). The expression levels of MIC-A/B, HLA class I and PD-L1 were significantly lower in the MCF7 cells than in those of the MDA-MB-231 cells (18.59 vs. $61.48,77.62$ vs. 98.03 , and 2.95 vs. $88.41 \%$, respectively) (Fig. 2D-F).

Effects of doxorubicin on modulation of TRAIL receptor, FasR, MIC-A/B, HLA class I and PD-L1 expression. The immune-modulation activity of doxorubicin has previously been reported (22); however, its effect in modulating NK cell-related markers is under-investigated. We hypothesized that the expression of TRAIL receptors, FasR, MIC-A/B, HLA class I and PD-L1 may modulate the sensitivity of BC cells to NK cells. First, the cytotoxicity of doxorubicin was determined using a cell viability assay, and the $\mathrm{CC}_{50}$ was determined after a 24-h treatment with doxorubicin. From this analysis, the MDA-MB-231 cells had a $\mathrm{CC}_{50}$ at a concentration of $0.9 \mu \mathrm{M}$, whereas the MCF7 cells were more resistant to doxorubicin with a higher $\mathrm{CC}_{50}$ concentration of $2.2 \mu \mathrm{M}$ (Fig. 3).

The sublethal dose of doxorubicin $(160 \mathrm{nM})$ was selected and tested for its activity in modulating TRAIL receptor, FasR, MIC-A/B, HLA class I and PD-L1 expression (Figs. 4 and S1-S3). Treatment with $160 \mathrm{nM}$ doxorubicin in the MDA-MB-231 cells caused a significant reduction in TRAIL2, whereas no significant alteration in other proteins was observed (Fig. 4A). By contrast, doxorubicin treatment at the same concentration significantly increased the expression level of FasR in the MCF7 cells, but it had only a slight non-significant effect on the expression levels of the other markers (Fig. 4B). The dosing effect of doxorubicin in modulating the expression of FasR in the MCF7 cells at the mRNA and protein levels was further investigated. qPCR analysis demonstrated that doxorubicin treatment elevated the mRNA expression of FasR in a dose-dependent manner. At a concentration of $160 \mathrm{nM}$, the doxorubicin-treated MCF7 cells reached a 2.77-fold increase in the mRNA expression of FasR compared with that of the non-treated control (Fig. 4C). Concordantly, the percentages of FasR-positive cells were significantly increased as doxorubicin concentrations increased compared with that of the control (Fig. 4D).

Doxorubicin sensitization increases NK-92 cytotoxicity in MCF7 cells. Based on the flow cytometric results, it was speculated that the expression profiles of FasR, PD-L1 and HLA class I may play an important role in MCF7 sensitivity to NK cells. Additionally, the treatment with doxorubicin resulted in an increase in FasR expression in the MCF7 cells, but not in the MDA-MB-231 cells. It was then investigated whether this 

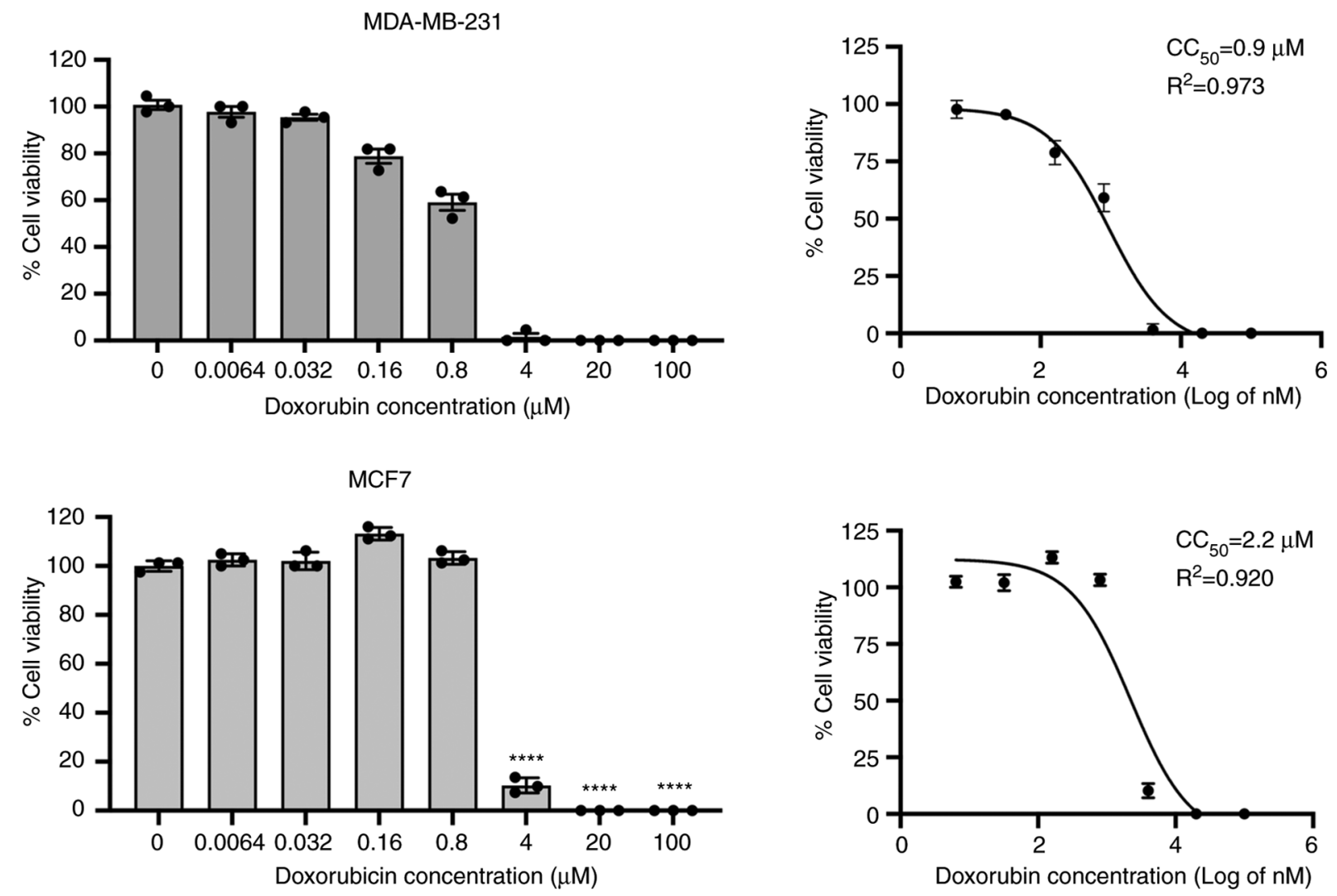

Figure 3. Cytotoxicity of doxorubicin in two different breast cancer cell lines. The cytotoxicity of doxorubicin at various concentrations $(0-100 \mu \mathrm{M})$ was determined in the MDA-MB-231 cells (top panel) and the MCF7 cells (bottom panel) using a cell viability assay. The percentages of cell viability after a $24-\mathrm{h}$ treatment with doxorubicin relative to the non-treated control (set as 100\%) are represented in the bar graphs (left). The half-maximal cytotoxic concentrations and $\mathrm{R}^{2}$ values were determined by using non-linear regression of GraphPad Prism software version 8 (GraphPad Software, Inc.) (right). Data were obtained from three independent experiments. Data are presented as the mean $\pm \mathrm{SEM} . \mathrm{CC}_{50}$, half-maximal cytotoxic concentration. ${ }^{* * * *} \mathrm{P}<0.0001$ vs. non-treated control $(\mu \mathrm{M})$.

A

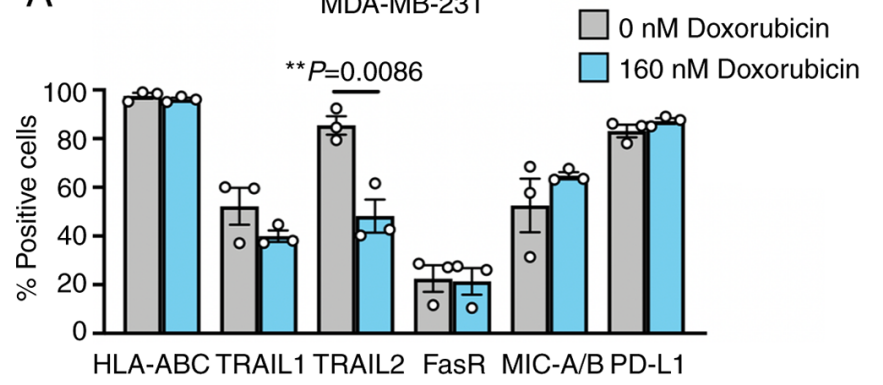

C

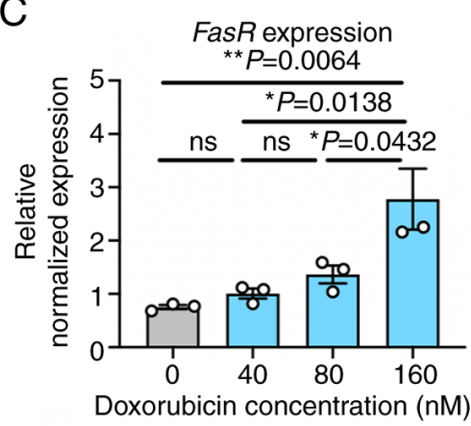

B

MCF7

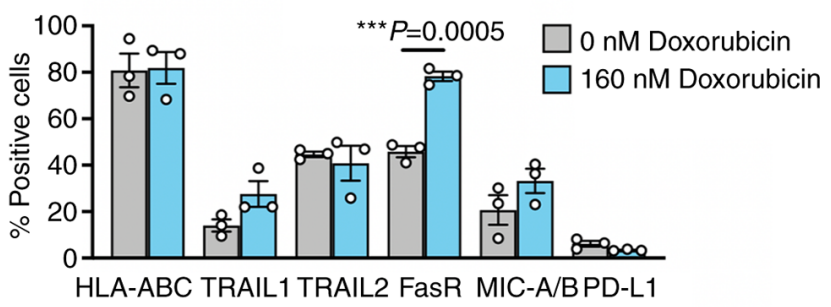

$\mathrm{D}$

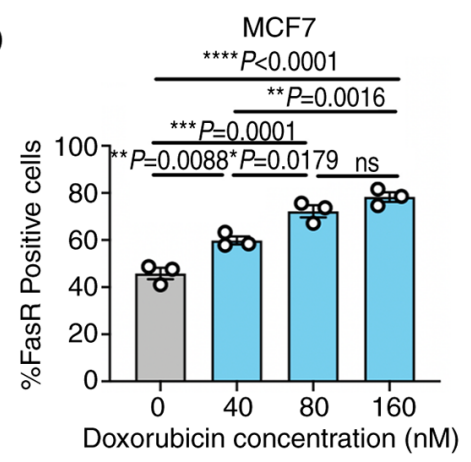

Figure 4. Effects of doxorubicin on the modulation of TRAIL receptor, FasR, MIC-A/B, HLA class I and PD-L1 expression in breast cancer cell lines. The MDA-MB-231 and MCF7 cells were treated with a sublethal dose of doxorubicin $(160 \mathrm{nM})$. The percentage of positive cells expressing TRAIL receptors, FasR, MIC-A/B, HLA class I and PD-L1 protein was monitored after a 24-h treatment with doxorubicin in (A) the MDA-MB-231 cells and the (B) MCF7 cells as analyzed by flow cytometry. The dose-dependent effects of doxorubicin on the expression of (C) FasR mRNA and the number of (D) FasR-positive cells were also examined. Data were obtained from three independent experiments. Data are presented as the mean \pm SEM. TRAIL, TNF-related apoptosis-inducing ligand; FasR, Fas receptor; HLA, human leukocyte antigen; PD-L1, programmed death-ligand 1; ns, not significant. 
A

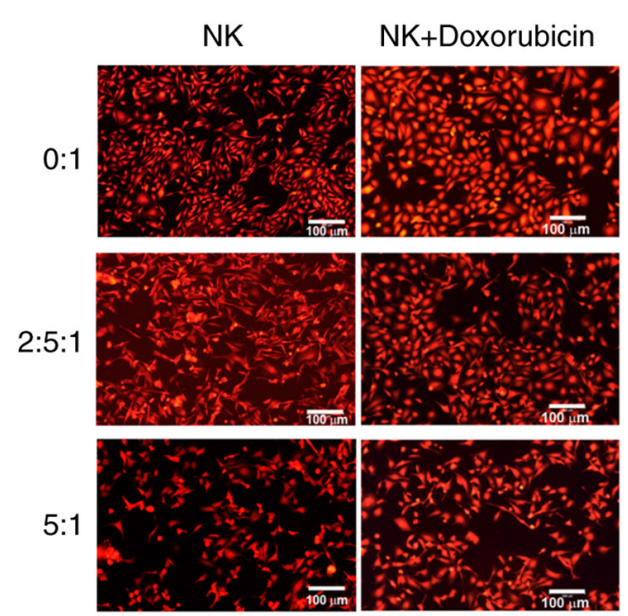

B

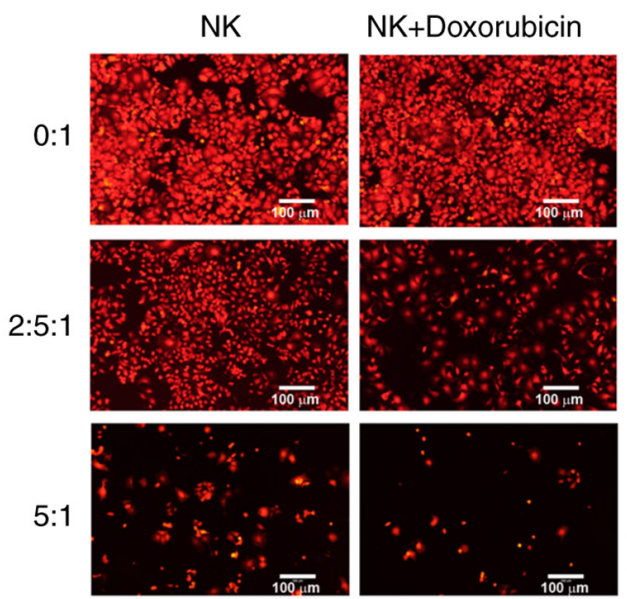

MDA-MB-231

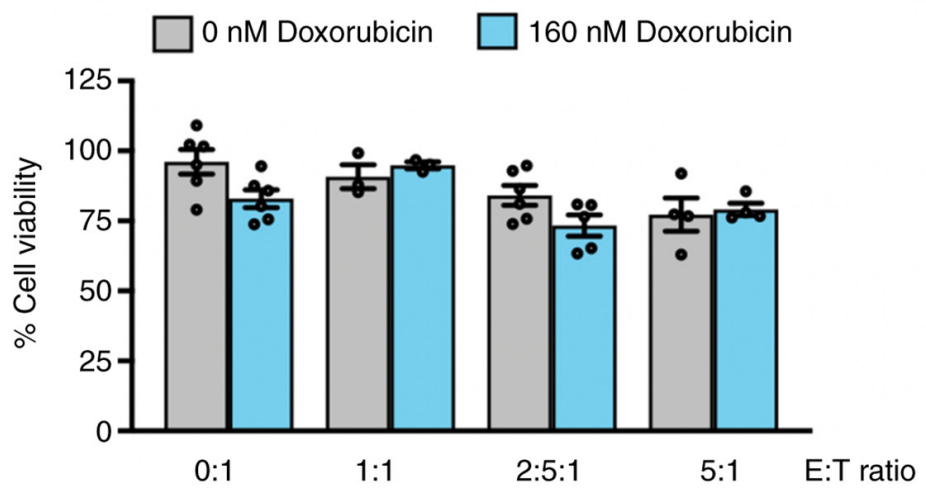

MCF7

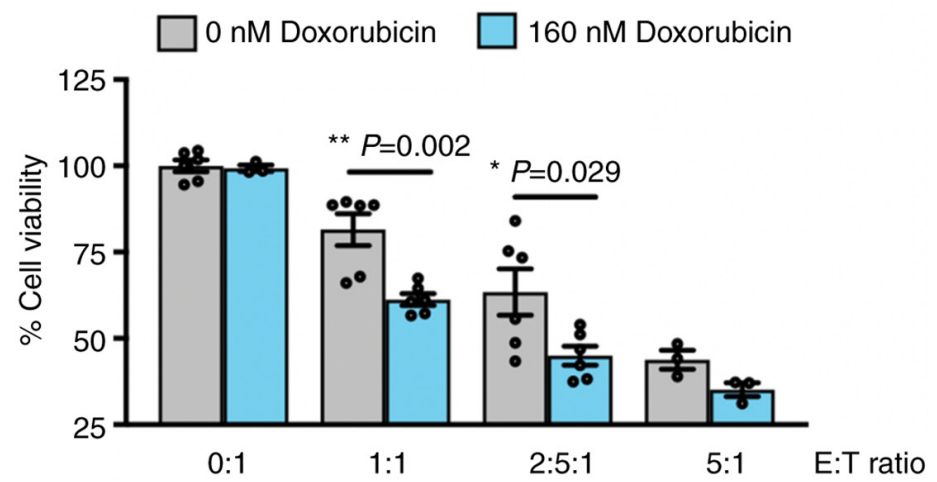

Figure 5. Doxorubicin sensitization increases NK cytotoxicity in the MCF7 cells. The effect of doxorubicin in sensitizing (A) the MDA-MB-231 cells and (B) the MCF7 cells to NK-92 cell killing was evaluated. The numbers of cancer cells after doxorubicin treatment, NK-92 cell treatment (at 2.5:1 and 5:1 E:T ratios), or treatment with a combination of doxorubicin and NK-92 cells were determined under a fluorescence microscope (left). The percentage of cancer cell viability was determined using crystal violet staining relative to the non-treated control (set as 100\%). The data were analyzed from at least three independent experiments. Data are presented as the mean \pm SEM. Scale bar, $100 \mu \mathrm{m}$. NK, natural killer; E, effector NK-92 cells; T, MCF7 or MDA-MB-231 target cells.

alteration in FasR expression sensitized the MCF7 cells and increased the cytotoxic activity of the NK-92 cells. The percentages of MDA-MB-231 and MCF7 cell death were compared after co-culturing with the NK-92 cells in the absence and presence of $160 \mathrm{nM}$ of doxorubicin. The results demonstrated that the NK-92 cells killed both types of cells in a dose-dependent manner (Fig. 5). Doxorubicin treatment exerted no additional killing effect of NK-92 cells in the MDA-MB-231 cells (Fig. 5A); however, it significantly increased the NK-92 cytotoxicity in the MCF7 cells (Fig. 5B). At E:T ratios of 1:1 and 2.5:1, doxorubicin treatment had a greater killing effect, as observed by a significant reduction in the MCF7 cell viability compared with the killing effect of the NK-92 cells alone. These results suggested the possible role of FasR in the modulation of NK-92 activity.

The effect of doxorubicin to increase the FasR expression and its relationship to enhance the NK killing activity were further investigated. Another BC cell line, T47D, was used to demonstrate the doxorubicin sensitization in $\mathrm{BC}$ cells Treatment of doxorubicin at $160 \mathrm{nM}$ increased the expression of FasR and the corresponding MFI (Fig. 6A). Notably, the doxorubicin treatment could sensitize T47D cells to the NK-92 killing activity, as shown by crystal violet staining to determine the amount of adherent living cells (Fig. 6B), which emphasized the contribution of FasR on modulating the NK-92 cytotoxicity.

The potential of doxorubicin in combination with the NK-92 cells was further examined in the present study using spheroid 3D culture to reflect its effect on controlling tumor mass. The MCF7 spheroids were generated and treated with doxorubicin at $320 \mathrm{nM}$ prior to co-culturing with the NK-92 cells. The number of living cells (green color) was monitored. The cell viability observed after 24 and $48 \mathrm{~h}$ of co-culturing with the NK-92 cells tended to decrease, particularly in the doxorubicin-treated cells (Fig. 7A and C). Notably, the NK-92 cells caused apparent destruction of the spheroids after $48 \mathrm{~h}$ of co-culturing, resulting in the collapse of the well-organized structure of spheroids in the doxorubicin-treated cells (Fig. 7B).

Doxorubicin markedly enhances cytotoxicity of primary NK cells. To confirm the effect of doxorubicin on cancer cell sensitization, the effect of doxorubicin on enhancing primary NK killing activity was investigated. Primary NK cells were isolated from the PBMCs of two healthy donors and were expanded ex vivo. After 6 days of expansion, the cells were 


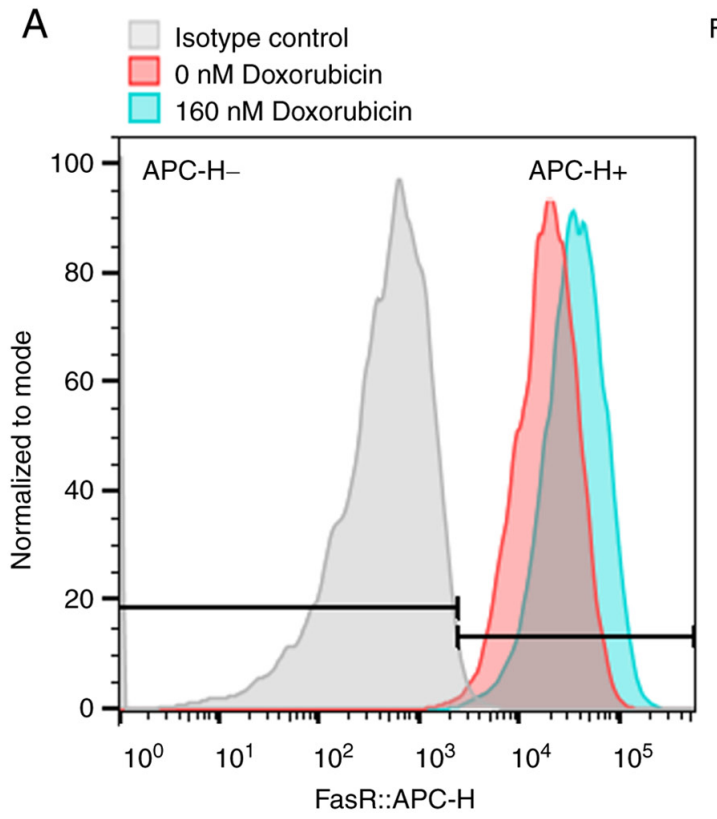

B
FasR expression in T47D cells

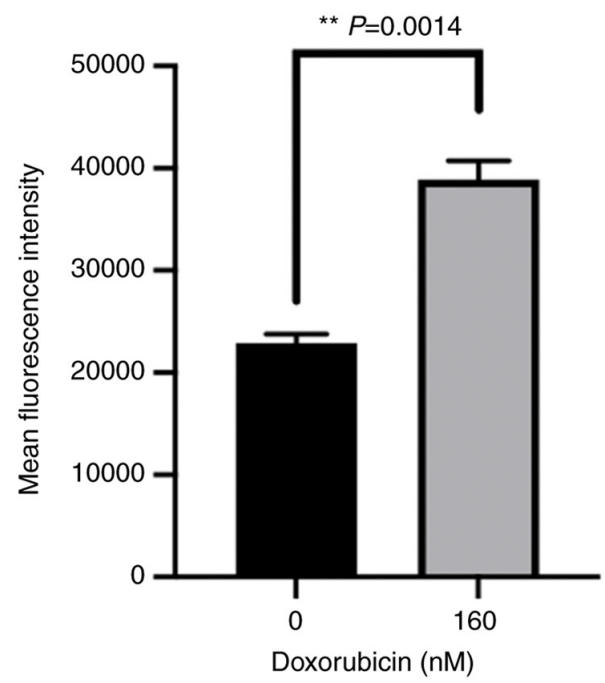

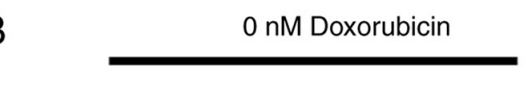

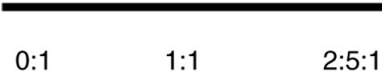

$2: 5: 1$

$0: 1$

$160 \mathrm{nM}$ Doxorubicin

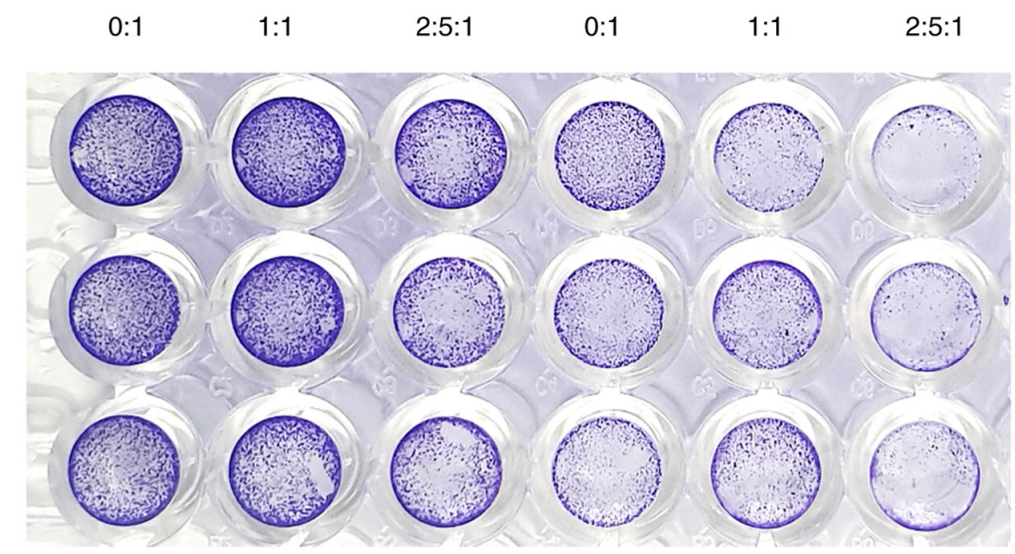

Figure 6. Doxorubicin sensitization increases NK cytotoxicity of the T47D breast cancer cells. (A) The effect of doxorubicin on FasR expression levels in the T47D cells was determined by flow cytometric analysis. The histograms demonstrate mean fluorescence intensities of the isotype control (gray), the untreated cells (pink) and the doxorubicin-treated cells (cyan). (B) Crystal violet staining of the T47D cells after the NK-92 cell treatment (at E:T ratios of 0:1, 1:1 and 2.5:1), or the combination of doxorubicin (160 nM) and NK-92 cell treatment. Data were obtained from three independent experiments. Data are presented as the mean \pm SEM. NK, natural killer; E, effector NK-92 cells; T, MCF7 or MDA-MB-231 target cells; APC, antigen presenting cells.

analyzed for CD45 (leukocyte common antigen), CD3 (T cell marker) and CD56 (NK cell marker) expression. The majority of cells after the expansion were $\mathrm{CD} 3{ }^{-} / \mathrm{CD} 56^{+} \mathrm{NK}$ cells, which also expressed CD16 at $67.78 \%$ (Fig. 8A). The cytotoxic capacity of primary NK cells to eliminate the MCF7 cells was then examined with and without doxorubicin treatment. Primary NK cells caused $\sim 66.78 \%$ cell death at an E:T ratio of 1:1 (Fig. 8B). As expected, this activity was significantly improved in the presence of $160 \mathrm{nM}$ doxorubicin, which resulted in $83.57 \%$ cell death (Fig. 8B). This finding strongly suggested the role of doxorubicin in enhancing primary NK killing activity.

\section{Discussion}

The use of immunotherapy to enhance immune response is currently the front-line strategy for cancer treatment and control. Among the different types of immune cells used to fight against cancer cells, NK cells are an attractive cellular immunotherapy strategy, as reflected by a large number of ongoing clinical trials (29). Without MHC restriction recognition and prior antigen exposure requirement, NK cells could be expanded ex vivo rapidly and transferred to patients within 5-12 days, depending on the production protocol $(30,31)$. NK-cell therapy could then be used as the first line of immunotherapy for cancer treatment. NK cells have been shown to play a vital role in controlling the formation and progression of BC. A comparison of BC growth and metastasis between NOD/SCID/ $\gamma$ null (NSG) mice (without T, B and NK cells) and SCID mice (with NK-cell, macrophage, complement and dendritic cell activities) demonstrated the important roles of NK cells for controlling BC growth and metastasis in SCID mice (32). These data emphasized the possibility of NK immunotherapy for BC treatment. However, the NK cell activity 


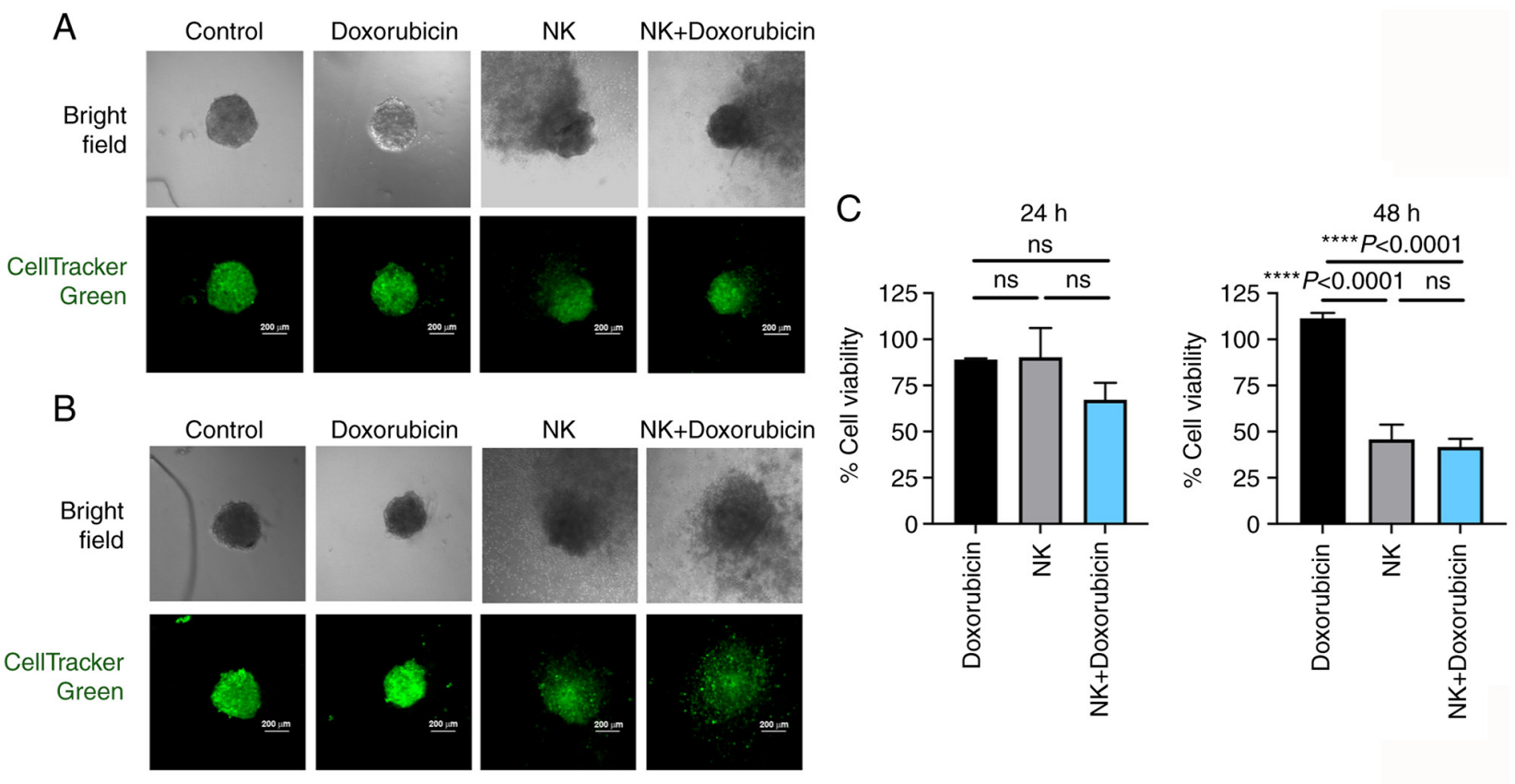

Figure 7. Doxorubicin sensitizes the MCF7 spheroid to be killed by the NK-92 cells. The effect of doxorubicin to sensitize the MCF7 cells to be susceptible to cytotoxicity by the NK-92 cells was evaluated in the spheroid model. The numbers of the MCF7 living cells (green) were monitored by confocal microscope at (A) $24 \mathrm{~h}$ and (B) $48 \mathrm{~h}$ after co-culturing with the NK-92 cells. The four experimental conditions included the untreated spheroid, the doxorubicin-treated spheroid, spheroid with the NK-92 cells, and the doxorubicin-treated spheroid and the NK-92 cells. (C) The viability of the MCF7 cells at 24 and $48 \mathrm{~h}$ after co-culture. The data were obtained from three independent experiments, which were normalized to the untreated control. Data are presented as the mean \pm SEM. NK, natural killer.
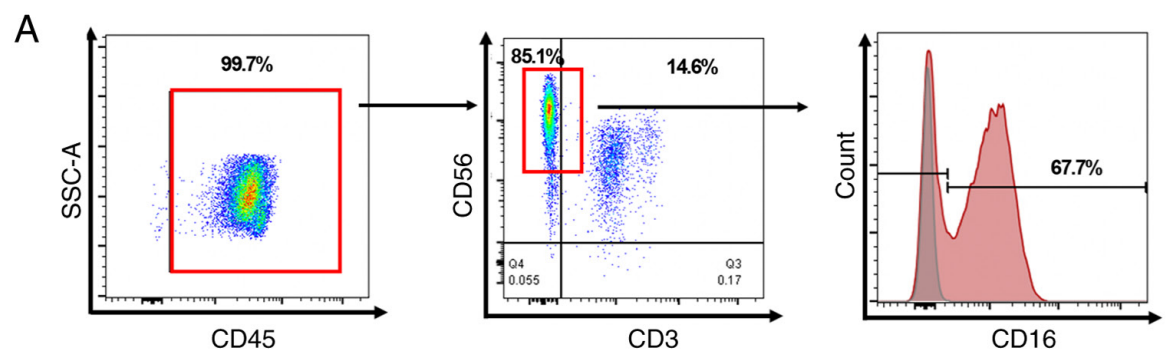

B
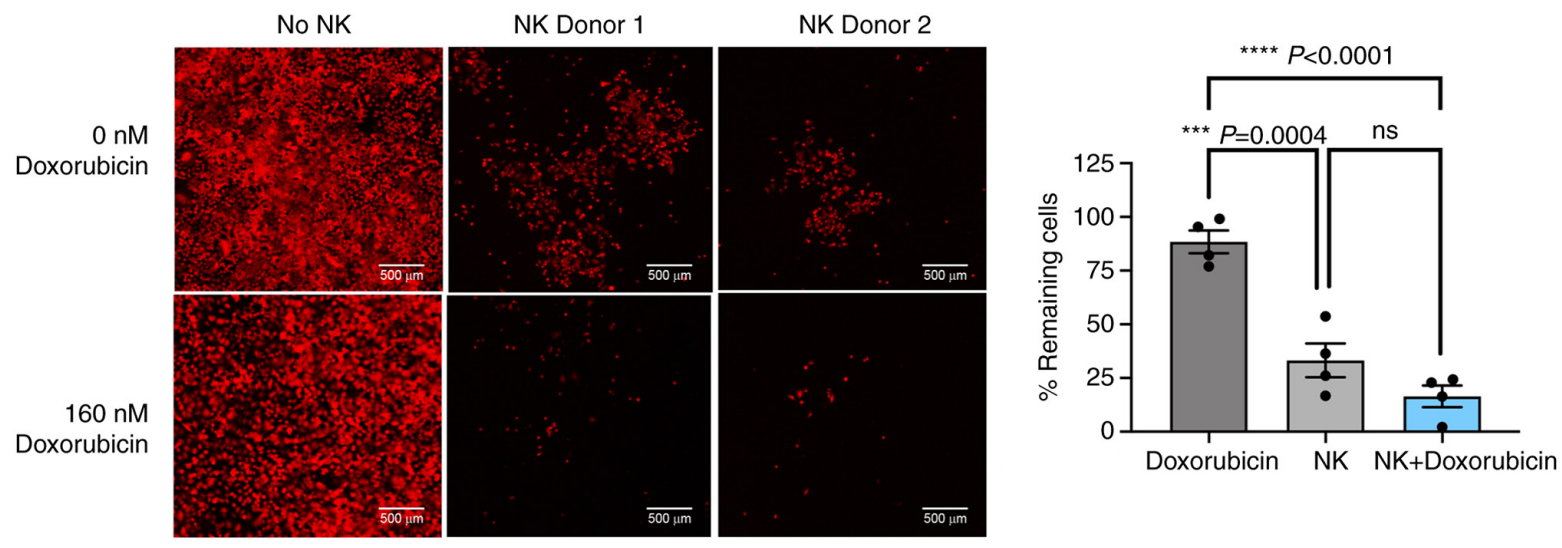

Figure 8. Combination of primary NK cells and doxorubicin increases MCF7 cell death. (A) Primary NK cells from two healthy donors were expanded and characterized for the expression of CD45, CD56, CD3 and CD16 using flow cytometric analysis. (B) The ability of primary NK cells to kill the MCF7 cells in the presence or absence of doxorubicin. Data are presented as the mean \pm SEM. NK, natural killer; ns, not significant.

after entering the body of the patient has been problematic, even though the number of NK cells has been found to be sufficient (18). Thus, the efficacy of NK cell therapy depends on both the quantity and quality of NK cells to achieve its therapeutic potential. In the present study, the combination of NK cells and a chemotherapeutic drug, doxorubicin, was demonstrated as a strategy for elevating NK cell activity. In addition, the association between the effect of doxorubicin 
treatment on FasR protein (CD95) expression modulation and NK killing ability was investigated.

Variations in tumor subpopulations caused by genetic or non-genetic factors, so-called heterogeneity, are known to exert significant influence on the outcome of cancer treatment (33). To understand the key natural differences that may have an impact on NK function, the efficiency of the $\mathrm{NK}$ cell line (NK-92) to eliminate well-known candidate $\mathrm{BC}$ cells $\left(\mathrm{ER}^{+} / \mathrm{PR}^{+} \mathrm{MCF} 7\right.$ and triple-negative MDA-MB-231 cells) was first compared in the present study. Naturally, the proportion of NK cells among peripheral blood lymphocytes is estimated to be 5-15\%; however, the density of NK cells is relatively higher at the tumor site and is associated with the tumor progression. Larsen et al (34) described the E:T ratio of intertumoral $\mathrm{NK}$ cells at the tumor site as 1:35, but with pro-NK cytokine such as IL2, the E:T ratio could reach 1:4 or better than 1:1. In the present experiment, the high E:T ratios of 2.5:1 and 5:1 were used to demonstrate the dose-dependent effect of NK-92 cells comparing between the different breast cancer cell lines. As expected, the MCF7 cells were more sensitive to the NK-92 cells than the MDA-MB-231 cells. This result necessitated further analysis of the biomarkers that manipulate the magnitude of NK cytotoxicity on these cells. Accordingly, the expression of five biomarkers that may play a role in NK cytotoxicity was compared, including TRAIL receptors (TRAIL1/TRAIL2), FasR (CD95), MIC-A/B, HLA class I and PD-L1. The results demonstrated that the NK-sensitive MCF7 cells had significantly lower expression of TRAIL receptors (TRAIL1/TRAIL2), MIC-A/B, HLA class I and PD-L1, whereas the expression of FasR was significantly higher than that observed in the MDA-MB-231 cells. Notably, the NK-92 cells express various activation molecules (NKp30, NKp46, 2B4, NKG2D, NKG2E and CD28), but only a few inhibitory molecules (NKG2A, NKG2B, low levels of KIR2DL4 and ILT-2), and they lack most of the killer inhibitory receptors (KIRs) (35); thus, the changes of HLA class I expression (as a ligand of KIRs) was considered as a minor response. In addition, the NK-92 cells expressed high levels of cytotoxic effector molecules, including the members of the TNF superfamily (i.e., FasL, TRAIL, TNF- $\alpha$ and TWEAK) suggesting the involvement of an alternative cytotoxic mechanism (35). Based on these findings, we hypothesized that the association of FasR and PD-L1 expression may contribute to the sensitivity of the MCF7 cells to the NK-92 cells.

FasR (CD95; TNF receptor superfamily member 6) is constitutionally expressed in human cells, and functions to mediate the antitumor cytotoxicity of NK cells and lymphocytes $(36,37)$. The specific interaction between FasR and its ligand (FasL) triggers apoptosis via a cascade of the extrinsic pathway in which the intracellular protein death-inducing signaling complex promotes the recruitment and activation of caspase- 8 , caspase- 3 and caspase- 7 cleavage (36). The signaling of FasR/FasL is considered to be one of the central cell-death mechanisms underlying the antitumor activity of immune cells. The resistance of cancer cells to cell death signaling has been reported as one of the hallmarks of cancer apart from continuous proliferation, growth suppression escape, effective angiogenesis, tissue invasion and metastasis (38). The induction of FasR/FasL expression was reported to augment the apoptotic rate in cancer. For example, the induction of
FasR by CD437 increased apoptosis in human non-small cell lung cancer (39). These data emphasized the impact of FasR expression on FasR/FasL signaling, which influences the modulation of NK cell function. Doxorubicin treatment in the present study caused the MCF7 and T47D cells to become more sensitive to NK cells. Notably, the upregulation of FasR expression was observed in both sensitive cells. This result was consistent with a previous report demonstrating that the combination of doxorubicin and immune cells increased cell death in various cancer cell types (22). In addition, the present study elucidated the partial involvement of FasR/FasL signaling in doxorubicin immunomodulation to enhance NK cell cytotoxicity against BC.

Apart from FasR/FasL signaling, chemotherapy treatment has been reported to promote sensitization of cancer cells via other mechanisms, i.e., the stress pathway and damage-associated molecular pattern (DAMP) (40). A low dose of doxorubicin has been reported to modulate the MIC-A/B and poliovirus receptor (CD155) via activation of ataxia telangiectasia mutated (ATM) and ATM- and Rad3-related protein kinase, resulting in the increase of NK activity in multiple myeloma models (41). Furthermore, several studies reported the effect of doxorubicin treatment on the upregulation of TRAIL receptors in various tumor cells via either p53-dependent or -independent mechanisms $(40,42,43)$. Increase of immunogenic potency through the DAMP immunogenic cell death pathway has been reported as one of the chemotherapy mechanisms. The interaction of DAMPs and their receptors promoted the recruitment and induction of immune cells, such as monocytes/dendritic cells, which ultimately modified the magnitude of immune cell activities (44). These mechanisms likely confer the sensitization of cancer cells to the immune cells. Since those potential mechanisms were not explored in the present study, they could not be excluded from the sensitization activity of doxorubicin to modulate BC to NK cells. Further investigation is required to confirm these mechanisms.

BC cell sensitization by doxorubicin could be applied to adoptive $\mathrm{T}$ cell therapy, since both perforin and FasL individually enhanced the killing ability of T cells and NK cells (45). A study of a putative perforin-independent mechanism revealed that the perforin deficient (-/-) cytotoxic T cells $\left(\mathrm{CD}^{+}\right)$were capable of inducing antigen-specific target cell lysis compared with $\mathrm{T}$ cells lacking both perforin and FasL, suggesting the additional contribution of FasR/FasL signaling in T cell killing activity (46). In the present study, primary NK cells demonstrated the improvement of killing activity in the doxorubicin-treated MCF7 cells. Notably, based on the results of flow cytometric analysis, although the major population of the present samples were the NK cells ( $~ 85 \%$ of NK cells), there were other immune cell populations that may contribute to the cancer cell death, particularly the $\mathrm{CD}^{+}$cells $(\sim 15 \%$ of population). Considering the contribution of FasL/FasR signaling on $\mathrm{T}$ cell cytotoxicity, the possibility that the induction of cell death in the doxorubicin-treated MCF7 cells may be the consequences of both NK cells and T cells could not be excluded.

A broad range of immunotherapeutic approaches has previously been developed. Adoptive immune cell therapy has been reported to treat $\mathrm{BC}(47)$, including conventional immune cells (i.e., NK cells) (48), cytokine-induced killer cells 
(CIK) (49), tumor-infiltrating lymphocytes (TILs) (50), genetically modified immune cells [i.e., chimeric antigen receptor (CAR)-T lymphocytes] $(51,52)$ and CAR-NK cells $(53-55)$. Doxorubicin could be used in combination with those cellular immuno-therapies or as an adjuvant therapy to enhance immune cell function, and to combat rapidly growing cancer cells and their strong microenvironment. The results of the present study suggested that FasR/FasL signaling plays an important role in immune cell function; however, the doxorubicin response was different among $\mathrm{BC}$ cell lines, MCF-7 and MDA-MB-231, suggesting heterogeneity in drug response.

In conclusion, the results of the present study demonstrated the role of FasR modulation in the response to doxorubicin treatment to enhance NK cell killing activity in BC cells. This finding supports the development and use of combined chemo-immunotherapy and immuno-modulation for the treatment of $\mathrm{BC}$.

\section{Acknowledgements}

The authors would like to thank Assistant Professor Kevin P. Jones (Faculty of Medicine Siriraj Hospital, Mahidol University, Thailand) for language editing of the original manuscript.

\section{Funding}

The present study was supported by the Center of Excellence on Medical Biotechnology (CEMB) (grant no. R000018103), the S\&T Postgraduate Education and Research Development Office, the Commission on Higher Education (Thailand), the Siriraj Research Fund (grant no. R016034008) Faculty of Medicine Siriraj Hospital, Mahidol University, and partially supported by the Research Center in Bioresources for Agriculture, Industry and Medicine, Chiang Mai University. A ChalermphrakiatGrantalso provided by the Faculty of Medicine Siriraj Hospital, Mahidol University. A Siriraj Graduate Scholarship from the Faculty of Medicine Siriraj Hospital, Mahidol University and grant from the National Research Council of Thailand (grant no. NRCT5-RGJ63012-126) was also provided. A Science Achievement Scholarship of Thailand also supported the study.

\section{Availability of data and materials}

The datasets used and/or analyzed during the current study are available from the corresponding author upon reasonable request.

\section{Authors' contributions}

NS planned the studies, designed and conducted experimental works, analyzed data and edited the manuscript. MW and NT conducted the primary NK isolation and culture, and edited the manuscript. NP conducted the killing assay. CC conducted the RT-qPCR. CT designed experiments. PTY designed experiments and edited the manuscript. AP managed the research team, planned the studies, designed and conducted experiments, analyzed data, and drafted and edited the manuscript. NS and AP confirm the authenticity of all the raw data. All authors read and approved the final version of the manuscript.

\section{Ethics approval and consent to participate}

The present study was conducted according to the guidelines of the Declaration of Helsinki and was approved (approval no. COA 286/2021) by the Siriraj Institutional Review Board of the Faculty of Medicine Siriraj Hospital, Mahidol University, (Bangkok, Thailand).

\section{Patient consent for publication}

Not applicable.

\section{Competing interests}

The authors declare that they have no competing interests.

\section{References}

1. Sung H, Ferlay J, Siegel RL, Laversanne M, Soerjomataram I, Jemal A and Bray F: Global cancer statistics 2020: GLOBOCAN estimates of incidence and mortality worldwide for 36 cancers in 185 countries. CA Cancer J Clin 71: 209-249, 2021.

2. Lakha H, Suriyawongpaisul P, Sangrajrang S, Leerapan B and Coker R: Breast cancer in Thailand: Policy and health system challenges to universal healthcare. Health Policy Plan 35: 1159-1167, 2020.

3. Treating Breast Cancer. https://www.cancer.org/cancer/breastcancer/treatment.html. Accessed October 23, 2021.

4. Saadatmand S, Bretveld R, Siesling S and Tilanus-Linthorst MM: Influence of tumour stage at breast cancer detection on survival in modern times: Population based study in 173,797 patients. BMJ 351: h4901, 2015.

5. Donegan WL: Tumor-related prognostic factors for breast cancer. CA Cancer J Clin 47: 28-51, 1997.

6. Robbins GF and Berg J: Curability of patients with invasive breast carcinoma based on a 30-year study. World J Surg 1: 284-286, 1977.

7. Farkona S, Diamandis EP and Blasutig IM: Cancer immunotherapy: The beginning of the end of cancer? BMC Med 14: 73, 2016.

8. Kruger S, Ilmer M, Kobold S, Cadilha BL, Endres S, Ormanns S, Schuebbe G, Renz BW, D'Haese JG, Schloesser H, et al: Advances in cancer immunotherapy 2019 - latest trends. J Exp Clin Cancer Res 38: 268, 2019.

9. Vaddepally RK, Kharel P, Pandey R, Garje R and Chandra AB: Review of indications of FDA-approved immune checkpoint inhibitors per NCCN Guidelines with the level of evidence. Cancers (Basel) 12: 738, 2020.

10. Twomey JD and Zhang B: Cancer immunotherapy update: FDA-approved checkpoint inhibitors and companion diagnostics. AAPS J 23: 39, 2021.

11. Nguyen LT, Saibil SD, Sotov V, Le MX, Khoja L, Ghazarian D, Bonilla L, Majeed H, Hogg D, Joshua AM, et al: Phase II clinical trial of adoptive cell therapy for patients with metastatic melanoma with autologous tumor-infiltrating lymphocytes and low-dose interleukin-2. Cancer Immunol Immunother 68: 773-785, 2019.

12. Multhoff G, Seier S, Stangl S, Sievert W, Shevtsov M, Werner C, Pockley AG, Blankenstein C, Hildebrandt M, Offner R, et al: Targeted natural killer cell-based adoptive immunotherapy for the treatment of patients with NSCLC after radiochemotherapy: A randomized phase II clinical trial. Clin Cancer Res 26: 5368-5379, 2020.

13. Radosa JC, Stotz L, Muller C, Kaya AC, Solomayer EF and Radosa MP: Clinical data on immunotherapy in breast cancer. Breast Care (Basel) 15: 450-469, 2020.

14. Sanchez-Correa B, Valhondo I, Hassouneh F, Lopez-Sejas N, Pera A, Bergua JM, Arcos MJ, Bañas H, Casas-Avilés I, Durán E, et al: DNAM-1 and the TIGIT/PVRIG/TACTILE axis: Novel immune checkpoints for natural killer cell-based cancer immunotherapy. Cancers (Basel) 11: 877, 2019.

15. Xie G, Dong H, Liang Y, Ham JD, Rizwan R and Chen J: CAR-NK cells: A promising cellular immunotherapy for cancer. EBioMedicine 59: 102975, 2020.

16. Liu S, Galat V, Galat Y, Lee YKA, Wainwright D and Wu J: NK cell-based cancer immunotherapy: From basic biology to clinical development. J Hematol Oncol 14: 7, 2021. 
17. Krause SW, Gastpar R, Andreesen R, Gross C, Ullrich H, Thonigs G,Pfister K and Multhoff G: Treatment of colon and lung cancer patients with ex vivo heat shock protein 70-peptide-activated, autologous natural killer cells: A clinical phase i trial. Clin Cancer Res 10: 3699-3707, 2004.

18. Parkhurst MR, Riley JP, Dudley ME and Rosenberg SA: Adoptive transfer of autologous natural killer cells leads to high levels of circulating natural killer cells but does not mediate tumor regression. Clin Cancer Res 17: 6287-6297, 2011.

19. Ruggeri L, Capanni M, Urbani E, Perruccio K, Shlomchik WD, Tosti A, Posati S, Rogaia D, Frassoni F, Aversa F, et al: Effectiveness of donor natural killer cell alloreactivity in mismatched hematopoietic transplants. Science 295: 2097-2100, 2002.

20. Geller MA and Miller JS: Use of allogeneic NK cells for cancer immunotherapy. Immunotherapy 3: 1445-1259, 2011.

21. Emens LA and Middleton G: The interplay of immunotherapy and chemotherapy: Harnessing potential synergies. Cancer Immunol Res 3: 436-443, 2015.

22. Wennerberg E, Sarhan D, Carlsten M, Kaminskyy VO, D'Arcy P, Zhivotovsky B, Childs R and Lundqvist A: Doxorubicin sensitizes human tumor cells to NK cell- and T-cell-mediated killing by augmented TRAIL receptor signaling. Int J Cancer 133: $1643-1652,2013$.

23. Thorn CF, Oshiro C, Marsh S, Hernandez-Boussard T, McLeod H, Klein TE and Altman RB: Doxorubicin pathways: Pharmacodynamics and adverse effects. Pharmacogenet Genomics 21: 440-446, 2011.

24. Paridaens R,BiganzoliL,Bruning P,Klijn JG,Gamucci T,Houston S, Coleman R, Schachter J, Van Vreckem A, Sylvester R, et al: Paclitaxel versus doxorubicin as first-line single-agent chemotherapy for metastatic breast cancer: A European organization for research and treatment of cancer randomized study with cross-over. J Clin Oncol 18: 724-733, 2000.

25. Livak KJ and Schmittgen TD: Analysis of relative gene expression data using real-time quantitative PCR and the 2(-Delta Delta C(T)) method. Methods 25: 402-408, 2001.

26. Jinushi M, Takehara T, Tatsumi T, Kanto T, Groh V, Spies T, Kimura R, Miyagi T, Mochizuki K, Sasaki Y and Hayashi N: Expression and role of MICA and MICB in human hepatocellular carcinomas and their regulation by retinoic acid. Int J Cancer 104: 354-361, 2003.

27. Jost $S$ and Altfeld M: Control of human viral infections by natural killer cells. Annu Rev Immunol 31: 163-194, 2013.

28. Quatrini L, Mariotti FR, Munari E, Tumino N, Vacca P and Moretta L: The immune checkpoint PD-1 in natural killer cells: Expression, function and targeting in tumour immunotherapy. Cancers (Basel) 12: 3285, 2020.

29. Oh S, Lee JH, Kwack K and Choi SW: Natural killer cell therapy: A new treatment paradigm for solid tumors. Cancers (Basel) 11: $1534,2019$.

30. Xie S, Wu Z, Niu L, Chen J, Ma Y and Zhang M: Preparation of highly activated natural killer cells for advanced lung cancer therapy. Onco Targets Ther 12: 5077-5086, 2019.

31. van Ostaijen-ten Dam MM, Prins HJ, Boerman GH, Vervat C, Pende D, Putter H, Lankester A, van Tol MJD, Zwaginga JJ and Schilham MW: Preparation of cytokine-activated NK cells for use in adoptive cell therapy in cancer patients: Protocol optimization and therapeutic potential. J Immunother 39: 90-100, 2016.

32. Dewan MZ, Terunuma H, Takada M, Tanaka Y, Abe H, Sata T, Toi M and Yamamoto N: Role of natural killer cells in hormone-independent rapid tumor formation and spontaneous metastasis of breast cancer cells in vivo. Breast Cancer Res Treat 104: 267-275, 2007

33. Marusyk A and Polyak K: Tumor heterogeneity: Causes and consequences. Biochim Biophys Acta 1805: 105-117, 2010.

34. Larsen SK, Gao Y and Basse PH: NK cells in the tumor microenvironment. Crit Rev Oncog 19: 91-105, 2014

35. Maki G, Klingemann HG, Martinson JA and Tam YK: Factors regulating the cytotoxic activity of the human natural killer cel line, NK-92. J Hematother Stem Cell Res 10: 369-383, 2001.

36. Hassin D, Garber OG, Meiraz A, Schiffenbauer YS and Berke G: Cytotoxic T lymphocyte perforin and Fas ligand working in concert even when fas ligand lytic action is still not detectable. Immunology 133: 190-196, 2011.

37. Peter ME, Hadji A, Murmann AE, Brockway S, Putzbach W, Pattanayak A and Ceppi P: The role of CD95 and CD95 ligand in cancer. Cell Death Differ 22: 885-886, 2015.

38. Hanahan D and Weinberg RA: Hallmarks of cancer: The next generation. Cell 144: 646-674, 2011
39. Sun SY, Yue P, Hong WK and Lotan R: Induction of fas expression and augmentation of fas/fas ligand-mediated apoptosis by the synthetic retinoid CD437 in human lung cancer cells. Cancer Res 60: 6537-6543, 2000

40. Zingoni A, Fionda C, Borrelli C, Cippitelli M, Santoni A and Soriani A: Natural killer cell response to chemotherapy-stressed cancer cells: Role in tumor immunosurveillance. Front Immunol 8: 1194, 2017.

41. Soriani A, Zingoni A, Cerboni C, Iannitto ML, Ricciardi MR, Di Gialleonardo V, Cippitelli M, Fionda C, Petrucci MT, Guarini A, et al: ATM-ATR-dependent up-regulation of DNAM-1 and NKG2D ligands on multiple myeloma cells by therapeutic agents results in enhanced NK-cell susceptibility and is associated with a senescent phenotype. Blood 113: 3503-3511, 2009.

42. Wen J, Ramadevi N, Nguyen D, Perkins C, Worthington E and Bhalla K: Antileukemic drugs increase death receptor 5 levels and enhance Apo-2L-induced apoptosis of human acute leukemia cells. Blood 96: 3900-3906, 2000.

43. Müller M, Wilder S, Bannasch D, Israeli D, Lehlbach K, Li-Weber M, Friedman SL, Galle PR, Stremmel W, Oren M and Krammer PH: P53 activates the CD95 (APO-1/Fas) gene in response to DNA damage by anticancer drugs. J Exp Med 188: 2033-2045, 1998

44. AsadzadehZ,SafarzadehE,SafaeiS, Baradaran A, Mohammadi A, Hajiasgharzadeh K, Derakhshani A, Argentiero A, Silvestris N and Baradaran B: Current approaches for combination therapy of cancer: The role of immunogenic cell death. Cancers (Basel) 12: 1047,2020

45. Kagi D, Vignaux F, Ledermann B, Bürki K, Depraetere V, Nagata S, Hengartner $H$ and Golstein P: Fas and perforin pathways as major mechanisms of T cell-mediated cytotoxicity. Science 265: 528-530, 1994

46. Kojima H, Shinohara N, Hanaoka S, Someya-Shirota Y, Takagaki Y, Ohno H, Saito T, Katayama T, Yagita $\mathrm{H}$ and Okumura K: Two distinct pathways of specific killing revealed by perforin mutant cytotoxic $\mathrm{T}$ lymphocytes. Immunity 1 : 357-364, 1994.

47. Sivaganesh V, Promi N, Maher S and Peethambaran B: Emerging immunotherapies against novel molecular targets in breast cancer. Int J Mol Sci 22: 2433, 2021

48. Shenouda MM, Gillgrass A, Nham T, Hogg R, Lee AJ, Chew MV, Shafaei M, Aarts C, Lee DA, Hassell J, et al: Ex vivo expanded natural killer cells from breast cancer patients and healthy donors are highly cytotoxic against breast cancer cell lines and patient-derived tumours. Breast Cancer Res 19: 76, 2017.

49. Mao Q, Li L, Zhang C, Sun Y, Liu S and Cui S: Clinical effects of immunotherapy of DC-CIK combined with chemotherapy in treating patients with metastatic breast cancer. Pak J Pharm Sci 28 (Suppl 3): S1055-S1058, 2015.

50. Zhang SC, Hu ZQ, Long JH, Zhu GM, Wang Y, Jia Y, Zhou J, Ouyang Y and Zeng Z: Clinical implications of tumor-infiltrating immune cells in breast cancer. J Cancer 10: 6175-6184, 2019.

51. Wallstabe L, Gottlich C, Nelke LC, Kuhnemundt J, Schwarz T, Nerreter T, Einsele H, Walles H, Dandekar G, Nietzer SL and Hudecek M: ROR1-CAR T cells are effective against lung and breast cancer in advanced microphysiologic 3D tumor models. JCI Insight 4: e126345, 2019.

52. Zhou R, Yazdanifar M, Roy LD, Whilding LM, Gavrill A, Maher J and Mukherjee P: CAR T cells targeting the tumor MUC1 glycoprotein reduce triple-negative breast cancer growth. Front Immunol 10: 1149, 2019.

53. $\mathrm{Hu} \mathrm{Z}$ : Tissue factor as a new target for CAR-NK cell immunotherapy of triple-negative breast cancer. Sci Rep 10: 2815,2020

54. Liu Y, Zhou Y, Huang KH, Fang X, Li Y, Wang F, An L, Chen Q, Zhang Y, Shi A, et al: Targeting epidermal growth factoroverexpressing triple-negative breast cancer by natural killer cells expressing a specific chimeric antigen receptor. Cell Prolif 53: e12858, 2020.

55. Chen X, Han J, Chu J, Zhang L, Zhang J, Chen C, Chen L, Wang Y, Wang H, Yi L, et al: A combinational therapy of EGFR-CAR NK cells and oncolytic herpes simplex virus 1 for breast cancer brain metastases. Oncotarget 7: 27764-27777, 2016.

This work is licensed under a Creative Commons Attribution-NonCommercial-NoDerivatives 4.0 International (CC BY-NC-ND 4.0) License. 